\title{
Evaluation and estimation of canopy heat storage fluxes in an apple orchard
}

\author{
Daiyu ITO* + , Sachinobu ISHIDA**, and Dai MATSUSHIMA*** \\ *Teaching and Research Center for Bio-coexistence, Faculty of Agriculture and Life Science, \\ Hirosaki University, 7-1, Shimobukuro, Fujisaki, Fujisaki, Aomori, 038-3802, Japan \\ **Graduate School of Science and Technology, Hirosaki University, \\ Bunkyo-cho, Hirosaki, Aomori, 036-8561, Japan \\ ***Faculty of Engineering, Chiba Institute of Technology, Tsudanuma, Narashino, Chiba, 275-0016, Japan
}

\begin{abstract}
To precisely evaluate the impact of canopy heat storage on the energy balance of an apple orchard, heat storage flux and its diurnal changes were examined by observation during both growing and sprouting periods. The majority of canopy heat storage was trunk heat storage, followed by sensible and latent heat storages, while the leaf heat storage was negligible. The canopy heat storage flux peaked between 0700 and 0930 and bottomed out at around 1800. The range of diurnal flux was larger in the sprouting period than in the growing period, and likewise on days of higher solar radiation. It reached $66 \mathrm{Wm}^{-2}$ on fine days in the sprouting period. By taking $\mathrm{HS}$ into account, the energy closure ratio for the eddy covariance method increased by 1.03 and 1.16 times in daytime and nighttime, respectively, and this increase was generally thought to improve the energy imbalance. The canopy heat storage flux could be well estimated from the difference of air temperature above the canopy at present and an hour before (RMSE $7 \mathrm{Wm}^{-2}$ ).
\end{abstract}

Key words: Energy balance closure, Fruit orchard, Micrometeorology, Sensible heat, Trunk.

\section{Introduction}

In recent years, although flux observations have been conducted at various sites all over the world to clarify carbon and/or water budgets, serious problems remain concerning the reliability of the observation. These include the energy imbalance in the eddy covariance method, in which the summation of the sensible heat flux $\left(H ; \mathrm{Wm}^{-2}\right)$ and the latent heat flux $\left(l E ; \mathrm{Wm}^{-2}\right)$ obtained by the turbulent observation does not satisfy the following energy balance equation:

$$
H+l E=R n-G-H S
$$

where $R n\left(\mathrm{Wm}^{-2}\right)$ and $G\left(\mathrm{Wm}^{-2}\right)$ represent the net radiation above the canopy and the soil heat storage flux at the ground surface, respectively. $H S\left(\mathrm{Wm}^{-2}\right)$ is the residual heat storage fluxes in the canopy other than the soil, consisting mainly of trunk, leaf, sensible,

Received; May 6, 2010.

Accepted; October 3, 2010.

†Corresponding Author: daiyu@cc.hirosaki-u.ac.jp latent and photosynthetic heat storages (Oliphant et al., 2004).

Wilson et al. (2002) analyzed the results of flux observations at 22 sites for 50 years which had been conducted by the eddy covariance method, and found that the mean energy closure ratio, $(H+l E) /(R n-G-H S)$, usually fell below 1 (mean of 0.84 ). Since the cause of this imbalance cannot be simply explained by the systematic observational error in $R n, G$, and $H S$ (Twine et al., 2000), it is very probable that the $H$ and $l E$ were underestimated for some reasons, such as advection, measurement errors in sonic anemometers (Gash and Dolman, 2003), and a loss of low frequency components (Cava et al., 2008). Therefore, $H$ and $l E$ are often corrected so that equation (1) is satisfied, and this correction is often also applied to the $\mathrm{CO}_{2}$ flux (Twine et al., 2000; Barr et al., 2007). If we are to correct turbulent fluxes accordingly, the energy terms of $R n, G$, and $H S$ must be accurately measured.

Also, in the Bowen ratio-energy budget method, the precision of calculated $H, l E$ and $\mathrm{CO}_{2}$ fluxes 
depend greatly on the accuracy of $R n, G$, and $H S$ because these fluxes are all determined in proportion to $(R n-G-H S)$.

Among $R n, G$, and $H S, H S$ is generally the smallest and moreover very laborious to evaluate correctly because many additional sensors must be equipped in the canopy to measure $H S$. For this reason, $H S$ has often been neglected in herbaceous communities. However, in forest communities, $H S$ is larger than that in herbaceous communities; by neglecting $H S$, the energy closure ratio was reported to decrease by 0.03 to 0.06 (Miura et al., 2003), 0.08 to 0.09 (Michiles and Gielow, 2008), 0.10 (Ohkubo et al., 2006), or 7\% (Wilson et al., 2002).

The authors have conducted flux observations in pear and apple orchards (Ito et al., 2006; Ito et al., 2009), but $H S$ has not been taken into account since $H S$ information related to fruit orchards remains very scare. Although fruit orchards generally have lower canopy heights and less biomass compared to forests, $H S$ should not be neglected if we are to observe $\mathrm{CO}_{2}$ and $\mathrm{H}_{2} \mathrm{O}$ fluxes as precisely as possible. In fact, in a corn field, the diurnal range in $H S$ reached $30 \mathrm{Wm}^{-2}$ (Meyers and Hollinger, 2004), despite having a lower canopy height compared to fruit orchards.

The objective of this study was to precisely evaluate the impact of $H S$ on the energy balance of an apple orchard. We observed trunk, leaf, sensible, and latent heat storage fluxes of our flux site in both April and September, and analyzed their diurnal pattern of changes. A method of estimating $H S$ from only the routine observations above and under the canopy, without conducting any additional observations within the canopy, is also proposed here.

\section{Materials and Methods}

\subsection{Site description}

Observations were conducted at and around the 9m-tall flux tower at Fujisaki farm, Hirosaki University $\left(40^{\circ} 39^{\prime} \mathrm{N}, 140^{\circ} 29^{\prime} \mathrm{E}\right)$, located in Fujisaki town, Aomori prefecture. The tower exists in an experimental apple orchard with an area of 0.4 ha. The apple trees in the orchard were mainly 28 years old in 2007, $4 \mathrm{~m}$ in height, and trained with central leaders. The apple varieties planted were "Fuji", "Starking Delicious", and "Mutsu". The inter-row and inter-tree distances were respectively $5.0 \mathrm{~m}$ and $3.5 \mathrm{~m}$, but were gradually extended to $7.0 \mathrm{~m}$ and $5.0 \mathrm{~m}$ by three rounds of alternate thinning conducted three times: partially in April 2006, then mostly in February 2008, and finally around the flux tower in May 2008 after the observations of this study were completed.

Investigation of the trees that were thinned in 2006 revealed that the fresh weight of trunk and stem, and their water content were $11.06 \mathrm{~kg} \mathrm{~m}^{-2}$ and $52 \%$, respectively. In November 2006 and 2007, just before defoliation, three trees were selected each year from the area with the original planting density, and were subjected to complete leaf picking. The fresh weight of the attached leaves, leaf water content and leaf area index (LAI) were $0.88 \mathrm{~kg} \mathrm{~m}^{-2}, 67 \%$, and 4.40 , respectively.

The experimental apple orchard described above was surrounded by another apple orchard containing trees of various varieties, and varying in shape and age. The apple orchard occupied approximately $90 \%$ of the area within $100 \mathrm{~m}$ from the tower, and $70 \%$ of that within $200 \mathrm{~m}$ from the tower. The remaining area was grassland or vegetable fields.

\subsection{Observations}

Routine observations were conducted continuously as follows. Air temperatures and relative humidities were measured by ventilated thermometer/hygrometers (Vaisala, HMP233 or HMP45) at heights of 4.5, 5.5, 7.0 , and $9.0 \mathrm{~m}$ on the tower. $R n$ was measured by a ventilated radiometer (EKO, MR-50) at a height of 9.0 $\mathrm{m}$. Soil temperatures were measured at 0.01 and 0.03 $\mathrm{m}$ underground by platinum resistance thermometers. The soil heat flux, $G_{-0.05}\left(\mathrm{Wm}^{-2}\right)$, was measured by four soil heat flow meters (EKO, MF-180F) at 0.05 $\mathrm{m}$ underground. Recently, almost all researchers have used the eddy covariance method to determine $\mathrm{CO}_{2}$ and water vapor fluxes, which was also performed at our observation site at a height of $9.0 \mathrm{~m}$.

Extensive observations were conducted twice for this study, in addition to the routine observations. The first round was conducted from September 3-30, 2007, when the apple leaves had fully expanded and fruits were growing (hereafter called the growing period). The second was conducted from April 6-25, 2008, from when the snow cover had completely melted until two weeks after sprouting (hereafter called the sprouting period). Air temperatures and relative humidities (or dew-point temperatures) were measured by ventilated thermometer/hygrometers (HMP233 or HMP45, Vaisala) or by hand-made thermocouples at heights of $0.5,1.5,2.5$, and $3.5 \mathrm{~m}$ on the tower. Moreover, two apple trees with intermediate growth 
near the tower were selected for trunk temperature measurement. Four thermocouples were buried for each tree at a depth of $0.02 \mathrm{~m}$, at the north and south faces of the trunk at heights of 1 and $2 \mathrm{~m}$.

All the measurements were conducted every $15 \mathrm{~s}$, and the averaged data were recorded every 2 min by a data logger.

\subsection{Calculation of $\mathrm{HS}$}

Since the eddy covariance method was performed at a height of $9.0 \mathrm{~m}$, more than twice as high as the vegetation, we regarded the space below $9.0 \mathrm{~m}$ as "inside the canopy," and $H S$ was calculated for the space below $9.0 \mathrm{~m}$ every $30 \mathrm{~min}$.

The sensible heat storage flux $\left(H S_{H}: \mathrm{Wm}^{-2}\right)$ and latent heat storage flux $\left(H S_{I E}\right.$ : $\left.\mathrm{Wm}^{-2}\right)$ were calculated using the following formulae:

$$
\begin{aligned}
H S_{H}= & \rho_{a} C_{p}\left(1.00 \Delta T_{0.5}+1.00 \Delta T_{1.5}+1.00 \Delta T_{2.5}\right. \\
& +1.00 \Delta T_{3.5}+1.00 \Delta T_{4.5}+1.25 \Delta T_{5.5} \\
& \left.+1.75 \Delta T_{7.0}+1.00 \Delta T_{9.0}\right) / 1800
\end{aligned}
$$

$$
\begin{aligned}
H S_{I E}= & \rho_{a} l\left(1.00 \Delta q_{0.5}+1.00 \Delta q_{1.5}+1.00 \Delta q_{2.5}\right. \\
& +1.00 \Delta q_{3.5}+1.00 \Delta q_{4.5}+1.25 \Delta q_{5.5} \\
& \left.+1.75 \Delta q_{7.0}+1.00 \Delta q_{9.0}\right) / 1800
\end{aligned}
$$

where $\rho_{\mathrm{a}}$ is the air density $\left(\mathrm{kg} \mathrm{m}^{-3}\right)$ determined depending on air temperature, $C_{p}$ is the specific heat of the air $\left(\mathrm{J} \mathrm{kg}^{-1}{ }^{\circ} \mathrm{C}^{-1}\right), \Delta T i$ is the increment of the mean air temperature $\left({ }^{\circ} \mathrm{C}\right)$ over $30 \mathrm{~min}(1800 \mathrm{~s})$ compared to that during the previous $30 \mathrm{~min}$ at a height of $i \mathrm{~m}, l$ is the latent heat of the water vapor $\left(\mathrm{J} \mathrm{kg}^{-1}\right)$, and $\Delta q i$ is the increment of the mean specific humidity $\left(\mathrm{kg} \mathrm{kg}^{-1}\right)$ over $30 \mathrm{~min}$ compared to that during the previous 30 min at a height of $i \mathrm{~m}$. The coefficients of $\triangle T i$ and $\Delta q i(1.00,1.25$, and 1.75) indicate the thickness (m) of the air layer as represented by each measurement. At layers below $4.5 \mathrm{~m}$, the volume of air excluded by the tree was not taken into consideration, because it was estimated at less than $1 \%$ of the total volume.

Trunk heat storage flux $\left(H S_{T}: \mathrm{Wm}^{-2}\right)$ was calculated using this formula:

$$
H S_{T}=W_{T} C_{T} \overline{\Delta T_{T}} / 1800
$$

where $W_{T}$ is the fresh weight of the trunk in the unit land area; the investigated value described in Section $2.1\left(11.06 \mathrm{~kg} \mathrm{~m}^{-2}\right)$ was used for both growing and sprouting periods. $\overline{\Delta T_{T}}$ is the increment of the mean temperature $\left({ }^{\circ} \mathrm{C}\right)$ at eight points on the trunk over 30 min compared to that during the previous $30 \mathrm{~min}$. $C_{T}$ is the specific heat of the trunk which was determined as follows according to Wada et al. (2002) and Miura et al. (2003):

$$
C_{T}=(1-m) C_{D}+m C_{W}+335
$$

where $m$ is the water content for the trunk, which was fixed as 0.52 in this study (although it slightly fluctuates throughout the year). $C_{W}$ is the specific heat of water $\left(4,190 \mathrm{~J} \mathrm{~kg}^{-1}{ }^{\circ} \mathrm{C}^{-1}\right), 335$ is the correction term (Skaar, 1988). $C_{D}$ is the specific heat of the dry wood $\left(\mathrm{J} \mathrm{kg}^{-1}{ }^{\circ} \mathrm{C}^{-1}\right)$, determined as follows depending on the mean temperature of the trunk $\left(\overline{T_{T}},{ }^{\circ} \mathrm{C}\right)$ :

$$
C_{D}=1113+4.85 \overline{T_{T}}
$$

The leaf heat storage flux $\left(H S_{L}: \mathrm{Wm}^{-2}\right)$ was neglected for the sprouting period, while calculated for growing period using this formula:

$$
H S_{L}=W_{L} C_{L} \Delta T_{L} / 1800
$$

where $W_{L}$ is the fresh weight of the leaf per unit land of area, namely $0.88 \mathrm{~kg} \mathrm{~m}^{-2}$ following the investigation described in Section 2.1. $C_{L}$ is the specific heat of the leaf, calculated as $3,253 \mathrm{~J} \mathrm{~kg}^{-1}{ }^{\circ} \mathrm{C}^{-1}$ because it contained $67 \%$ water $\left(4,190 \mathrm{~J} \mathrm{~kg}^{-1}{ }^{\circ} \mathrm{C}^{-1}\right)$ and the remaining $33 \%$ was mostly cellulose $\left(1,350 \mathrm{~J} \mathrm{~kg} \mathrm{k}^{-1}{ }^{\circ} \mathrm{C}^{-1}\right) . \Delta T_{L}$ is the increment of mean leaf temperature $\left({ }^{\circ} \mathrm{C}\right)$ over $30 \mathrm{~min}$ compared to that during the previous $30 \mathrm{~min}$, but the air temperature in the canopy was substituted for leaf temperature because leaf temperature is difficult to measure accurately.

\subsection{Calculation of $G$}

$G$ was calculated using the soil heat flux at a depth of $0.05 \mathrm{~m}\left(G_{-0.05}\right)$ and the heat storage between 0.00 and $0.05 \mathrm{~m}$. Namely,

$$
\begin{aligned}
G= & G_{-0.05} \\
& +C_{\text {soil }}\left(0.025 \Delta T_{-0.01}+0.025 \Delta T_{-0.03}\right) / 1800
\end{aligned}
$$

where $\Delta T_{-0.01}$ and $\Delta T_{-0.03}\left({ }^{\circ} \mathrm{C}\right)$ indicate the temperature changes of soils over $30 \mathrm{~min}$ at depths of 0.01 and $0.03 \mathrm{~m}$, respectively. $C_{\text {soil }}$ is the specific heat of the soil, regarded as $2.39 \times 10^{6} \mathrm{~J} \mathrm{~m}^{-3}{ }^{\circ} \mathrm{C}^{-1}$, although it fluctuates approximately $\pm 15 \%$ depending on the soil water content. The coefficient of $\Delta T i(0.025)$ indicates the thickness (m) of the soil layer as represented by each measurement. 


\section{Results and Discussion}

\subsection{Amount of each $H S$ component and its diur- nal change}

In this study, the observed data were grouped into three categories based on the relative level of daily solar radiation (downward shortwave radiation). Observations were grouped as "solar radiation level 1 " if the daily solar radiation was less than $35 \%$ of the potential solar radiation (Allen et al., 1998; 2005); "solar radiation level 2" if the rate was between 35 and $70 \%$; and "solar radiation level 3 " if the rate exceeded $70 \%$. The total observation days and the average amount of daily solar radiation for each group are shown in Table 1, while the diurnal change in mean solar radiation intensity for each category is illustrated in Fig. 1. Here, we can see that the mean solar radiation intensity fluctuated over time, and the diurnal solar radiation curves were asymmetric, especially in "level 1" and "level 2". These irregular changes in solar radiation in "level 1" and "level 2" may trigger noises on the diurnal changing patterns of heat storage flux components.

Among the four heat storage flux components investigated, $H S_{T}$ fluctuated most depending on the time of day. The diurnal change in $H S_{T}$ is shown in Fig. 2. The diurnal change pattern was very similar through the season and solar radiation level. Namely, $H S_{T}$ started to increase rapidly just before sunrise, peaking between 0700 and 0930 (JST), before decreasing and becoming negative around 1400 , and bottoming out around 1800 . Thereafter, it increased again, remaining negative until just before sunrise the following day. This diurnal change agreed very well with observations made in a larch forest in Hokkaido (Miura et al., 2003). However, if the trunk diameter is larger, the timing of the peak or lowest point will be delayed since the thermal conductivity of the trunk is thought to be less. In fact, $H S_{T}$ was reported to peak after 1200 in a temperate deciduous forest in the United
States (Oliphant et al., 2004) and a tropical rainforest (Michiles and Gielow, 2008).

The range of diurnal fluctuation (difference between the daily maximum and minimum) was larger in the sprouting period than in the growing period, and at higher solar radiation levels. It reached as much as 52 $\mathrm{Wm}^{-2}$ in the sprouting period at solar radiation level 3. In the sprouting period, there are almost no leaves and thus the trunk easily receives solar radiation, and this condition probably resulted in the large diurnal fluctuation in $H S_{T}$. The range of diurnal fluctuation for $H S_{T}$ as observed in this study was almost the same or even greater than those observed in various forests (Migliavacca et al., 2009; Michiles and Gielow, 2008; Oliphant et al., 2004), although the amount of trunk biomass (11.06 $\left.\mathrm{kg} \mathrm{FW} \mathrm{m}^{-2}\right)$ was smaller than those of forests (e.g. $43.79 \mathrm{~kg} \mathrm{FW} \mathrm{m}^{-2}$ as reported by Michiles and Gielow). However, the 28 year old apple trees in this study had thick trunks with an average basal area of $32 \mathrm{~m}^{2} \mathrm{ha}^{-1}$ (unpublished data), which was almost comparable to forest canopies. Moreover, the branch pruning conducted every year in the apple orchard may have resulted in good light penetration into the trunks. These conditions - large basal area and frequent branch pruning - may explain the large $H S_{T}$ fluctuation in the apple orchard of this study.

The heat storage component that showed the second largest diurnal fluctuation range was $H S_{H}$. As shown in Fig. 3, the diurnal pattern of change in $H S_{H}$ was very similar to $H S_{T}$, and also agreed well with those obtained in forest canopies (e.g. Miura et al., 2003). The diurnal range was larger for higher solar radiation levels, as was the case with $H S_{T}$, but with no conspicuous seasonal difference. This is probably because the experimental apple orchard was comparatively sparse and well ventilated, even during the growing period. The diurnal range of fluctuation was $16 \mathrm{Wm}^{-2}$ at maximum for solar radiation level 3. Although the range was larger than that obtained in a larch forest in Hokkaido (Miura et al., 2003), it was still far below those in a $20 \mathrm{~m}$ tall

Table 1. Number of observed days and daily mean solar radiation for each solar radiation level.

\begin{tabular}{ccccc}
\hline \multirow{2}{*}{$\begin{array}{c}\text { Solar } \\
\text { radiation } \\
\text { level }\end{array}$} & \multicolumn{2}{c}{ Growing period } & \multicolumn{2}{c}{ Sprouting period } \\
\cline { 2 - 5 } & $\begin{array}{c}\text { No. of } \\
\text { observed days }\end{array}$ & $\begin{array}{c}\text { Mean solar radiation } \\
\left(\mathrm{MJ} \mathrm{m}^{-2} \text { day }^{-1}\right)\end{array}$ & $\begin{array}{c}\text { No. of } \\
\text { observed days }\end{array}$ & $\begin{array}{c}\text { Mean solar radiation } \\
\left(\mathrm{MJ} \mathrm{m}^{-2} \text { day }^{-1}\right)\end{array}$ \\
\hline 1 & 8 & 5.19 & 4 & 6.63 \\
2 & 5 & 9.89 & 3 & 14.37 \\
3 & 15 & 18.20 & 9 & 21.56 \\
\hline
\end{tabular}




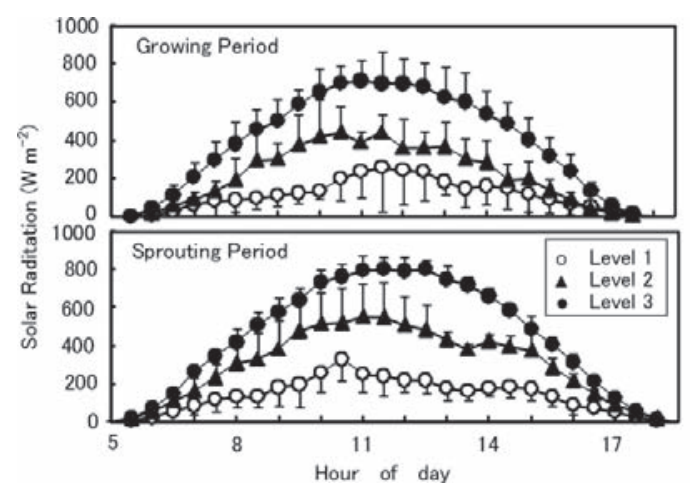

Fig. 1. Diurnal changes in averaged solar radiation intensity for each solar radiation level. Vertical bars indicate standard deviations.

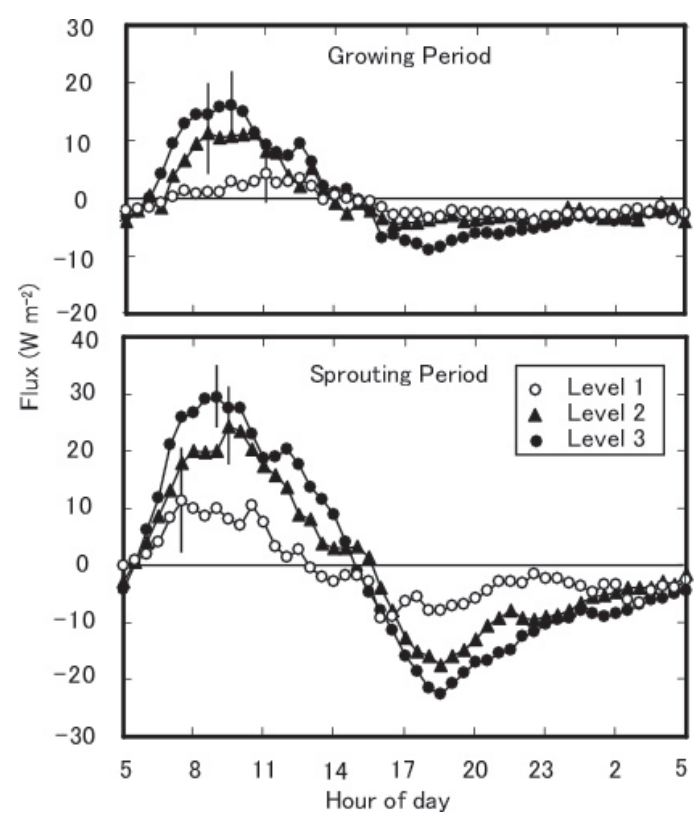

Fig. 2. Diurnal changes in trunk heat storage flux under various levels of solar radiation. Vertical bars indicate standard deviations at the times of diurnal maximum.

temperate deciduous forest (Oliphant et al., 2004) or a tropical rainforest (Ohkubo et al., 2006; Michiles and Gielow, 2008) where the sensible heat storage flux reached 30 to $100 \mathrm{Wm}^{-2}$, becoming the primary heat storage component of the canopy. Thus, in the apple orchard, we can conclude that the most important heat storage term is $H S_{T}$, and that $H S_{H}$ is generally not as important as in forests.

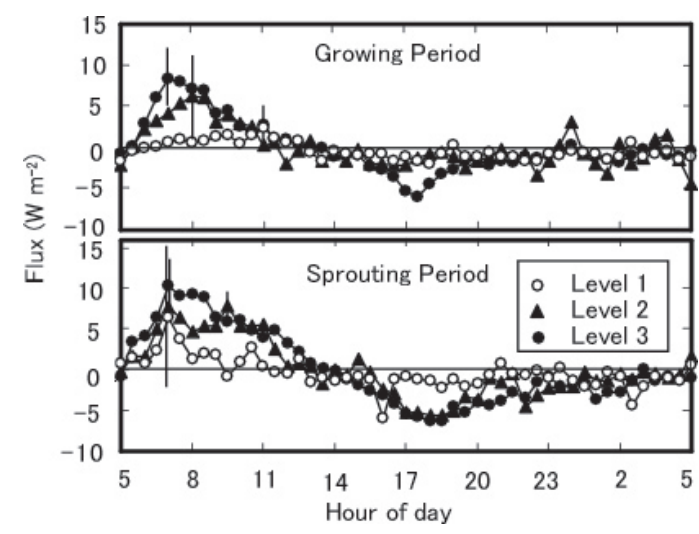

Fig. 3. Diurnal changes in sensible heat storage flux under various levels of solar radiation. Vertical bars indicate standard deviations at the times of diurnal maximum.



Fig. 4. Diurnal changes in latent heat storage flux under various levels of solar radiation. Vertical bars indicate standard deviations at the times of diurnal maximum.

The diurnal change in $H S_{I E}$ is shown in Fig. 4. The flux tended to become large between 0700 and 0930, as was the case with $H S_{T}$ and $H S_{H}$. However, the diurnal change, seasonal difference, and the difference among the solar radiation levels remained unclear. The fluctuation of $H S_{I E}$ was small, ranging between -5 to $5 \mathrm{Wm}^{-2}$, but with occasional exceptional observations. According to McCaughey and Saxton (1988), $H S_{I E}$ increasingly fluctuates at times of rainfall, becoming the primary heat storage component. Michiles and Gielow (2008) observed an extremely low HS (below 




Fig. 5. Diurnal changes in leaf heat storage flux in the growing period under various levels of solar radiation. Vertical bars indicate standard deviations at the times of diurnal maximum.



Fig. 6. Diurnal changes in total heat storage flux under various levels of solar radiation. Vertical bars indicate standard deviations at the times of diurnal maximum.

$-200 \mathrm{Wm}^{-2}$ ) at the time of rainfall in a tropical rainforest canopy. In our observations, $H S_{I E}$ fell below $-20 \mathrm{Wm}^{-2}$ three times, all of which occurred during or just after rainfall (data not shown).

The diurnal change in $H S_{L}$ in the growing period is shown in Fig. 5. $H S_{L}$ remained almost constantly within the range of $\pm 2 \mathrm{Wm}^{-2}$, and was the smallest of the four heat storage components. Therefore, $H S_{L}$ seemed negligible for flux observation in an apple orchard.

Finally, $H S$ was calculated by summing up the four heat storage flux components; its diurnal change is shown in Fig. 6. HS showed diurnal changes similar to those in $H S_{T}$, which was the largest contributing component. The diurnal flux fluctuation range was larger in the sprouting period, probably due to better light penetration into the trunk, and at higher solar radiation levels. At solar radiation level 3, the range of diurnal fluctuation reached $66 \mathrm{Wm}^{-2}$ for the sprouting period, as opposed to $44 \mathrm{Wm}^{-2}$ for the growing period. However, during the growing period, photosynthetic heat storage had to be taken into account, in addition to the four heat storage flux components. Preliminary analysis of the $\mathrm{CO}_{2}$ flux at our site revealed that averages of 23 and $9 \mathrm{~g} \mathrm{~m}^{-2} \mathrm{CO}_{2}$ were absorbed and evolved during daytime and nighttime, respectively, in June 2008 (Ito et al., 2009). These corresponded to photosynthetic heat storages of 5 and $-2 \mathrm{Wm}^{-2}$, respectively. Therefore, the range of diurnal fluctuation for $H S$ in the growing period may exceed $50 \mathrm{Wm}^{-2}$ if the photosynthetic heat storage is taken into account.

Since $H S_{T}$ contributed most to $H S$, the trunk biomass will probably play an important role in determining $H S$ in an apple orchard. The trunk fresh weight was $11.06 \mathrm{~kg} \mathrm{~m}^{-2}$ in our experimental site, but it fluctuates drastically depending on the tree age and rootstock. For example, Fukuda and Takishita (1993) reported that it was $2.95 \mathrm{~kg} \mathrm{~m}^{-2}$ for 16 year old apple trees grafted on invigorating rootstocks, as opposed to $1.44 \mathrm{~kg} \mathrm{~m}^{-2}$ for 10 year old apple trees grafted on dwarf rootstocks. Therefore, it must be noted that the results of this study cannot be adapted directly to other apple orchards.

\subsection{The impact of $\boldsymbol{H S}$ on flux observation}

In the Bowen ratio-energy budget method, $H, l E$ and $\mathrm{CO}_{2}$ fluxes are proportional to $(R n-G-H S)$. To evaluate the error that will arise by neglecting $H S$ and substituting $(R n-G-H S)$ for $(R n-G)$, we examined the value $(R n-G) /(R n-G-H S)$ every $30 \mathrm{~min}$ of the day, including both periods and every solar radiation level (Fig. 7). The results suggest that fluxes will be overestimated except for an hour just before sunrise (0500 to 0600) and for three hours in the afternoon (1330 to 1630), and that severe overestimations exceeding 20\% will occur just after sunrise and just after sunset. Next, we separated daytime (0600 to 1800) and nighttime (1800 to 0600) data and performed regression analysis of $(R n-G)$ against $(R n-G-H S)$. As shown in Fig. 8, very close relationships existed and the following two regression equations were obtained. For daytime data:

$$
R n-G=1.03(R n-G-H S)
$$




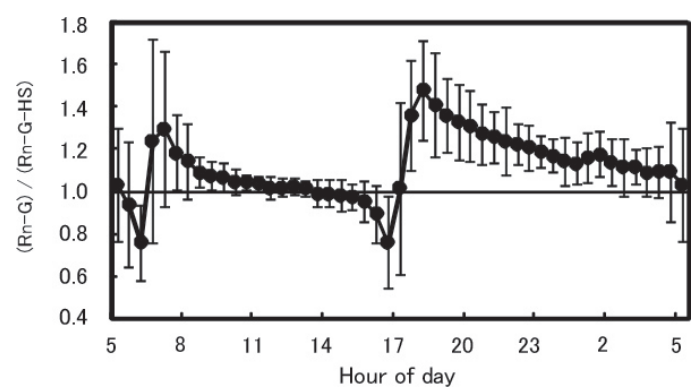

Fig. 7. Diurnal changes in the ratio $(R n-G) /(R n-$ $G-H S$ ) throughout the observations. Vertical bars indicate standard deviations.

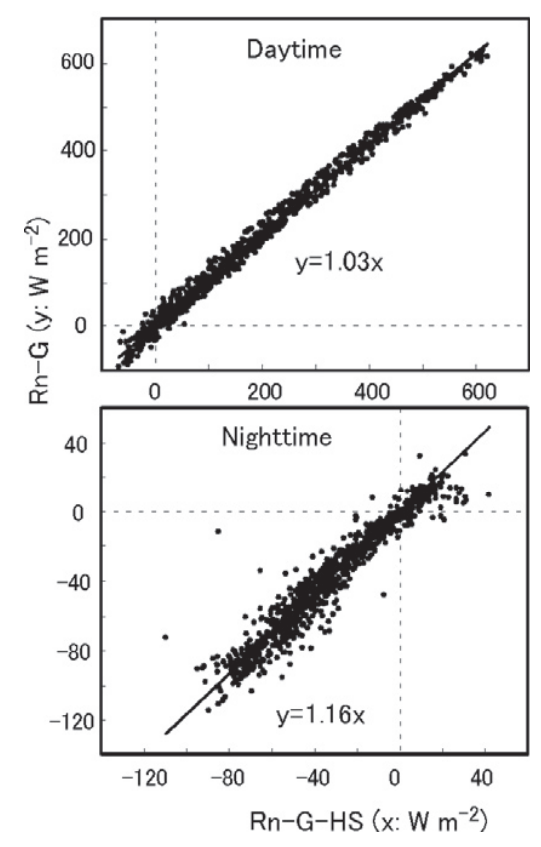

Fig. 8. Relationships between $(R n-G-H S)$ and $(R n-G)$ for daytime and nighttime throughout the observations.

For nighttime data:

$$
R n-G=1.16(R n-G-H S)
$$

From equations (9) and (10), we can suggest that overestimations of about 3 and 16\% will occur in daytime and nighttime respectively, by neglecting $H S$ in the Bowen ratio-energy budget method. This suggestion is also true for the energy closure ratio, $(H+l E) /(R n-G-H S)$, in the eddy covariance method, because we can easily derive the following equations from equations (9) and (10).

$$
\begin{aligned}
(H & +l E) /(R n-G-H S) \\
& =1.03(H+l E) /(R n-G) \\
(H & +l E) /(R n-G-H S) \\
& =1.16(H+l E) /(R n-G)
\end{aligned}
$$

In other words, we can expect the energy closure ratio to increase by 1.03 and 1.16 times in daytime and nighttime respectively, by taking $H S$ into account, and this increase is generally thought to improve the energy imbalance of the observation site.

\subsection{Estimation of $\mathrm{HS}$}

It has been reported that $H S_{T}$ or $H S_{H}$ can be estimated reasonably well from the change in the air temperature above the canopy (McCaughey and Saxton, 1988; Wada et al., 2002; Michiles and Gielow, 2008). Because $H S_{T}$ and $H S_{H}$ were the first and second most important components of $H S$ in this study respectively, we compared $H S$ and the hourly change (from 30 minutes before to 30 minutes after) in the air temperature above the canopy (at 9.0 m). As illustrated in Fig. 9 for the growing period, the two values showed quite similar diurnal trends. However, they seemed to be slightly out of phase: the peak of $H S$ often appeared $30 \mathrm{~min}$ after that of the temperature change. Such phase shift was also reported by Michiles and Gielow (2008), probably

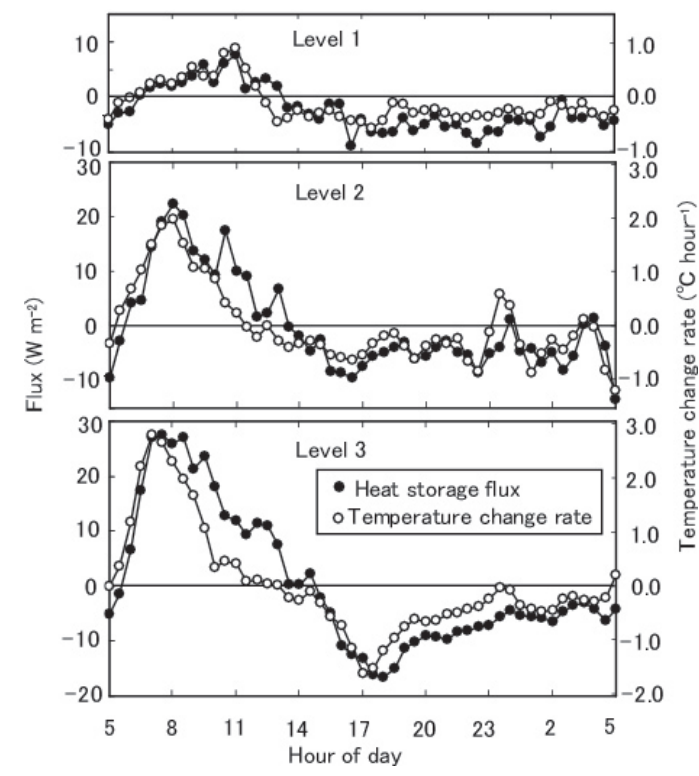

Fig. 9. Comparisons between the diurnal changes in total heat storage flux and air temperature change rate for growing period under various levels of solar radiation. 


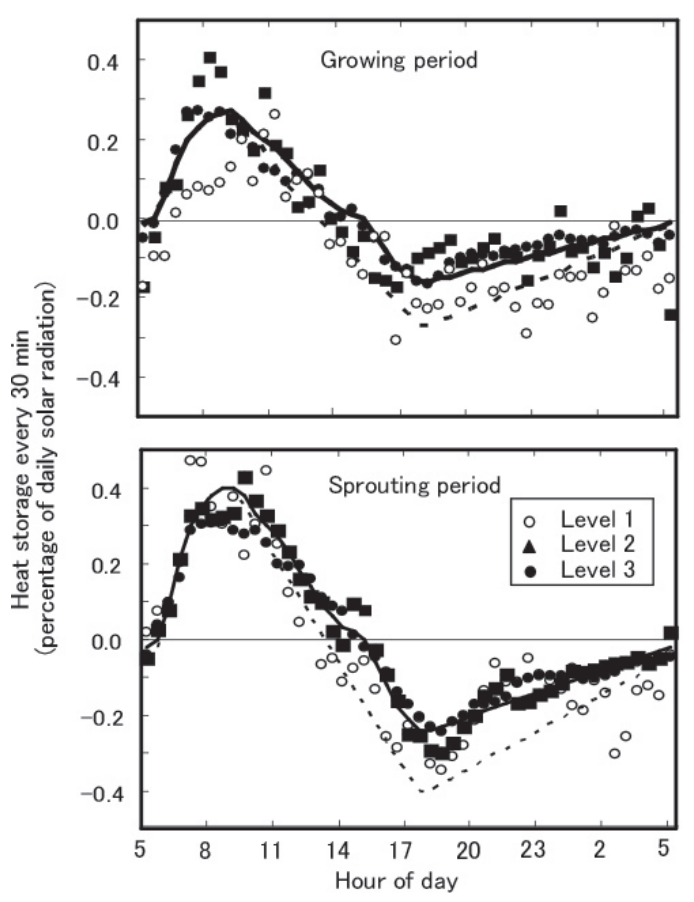

Fig. 10. Diurnal changes in total heat storage flux every 30 min expressed as the percentage of daily solar radiation under various levels of solar radiation.

Dashed and solid lines indicate the approximation for level 1 and for levels 2 and 3, respectively.

due to the thermal conductivity of the trunk. We thus conducted a regression analysis by shifting the phase of temperature change by $30 \mathrm{~min}$, and obtained the following equation for the growing period:

$$
H S=9.81(T[0]-T[-1])
$$

and for the sprouting period,

$$
H S=13.15(T[0]-T[-1])
$$

where $T[0]$ and $T[-1]$ are air temperatures above the canopy at present and 1 hour before, respectively. The rates of contribution for equations (11) and (12) were 0.68 and 0.86 , respectively, suggesting that $H S$ will be successfully estimated using these equations. The coefficients in equations (11) and (12), 9.81 and 13.15, are likely to reflect the rate of solar radiation to which the surface of the trunk exposed. During the sprouting period, higher value of the coefficient is probably due to the better light penetration into the trunk, because almost no leaf exists. Accordingly, it might be possible to estimate $H S$ in another period by adjusting this coefficient depending on LAI.

In Fig. 10, $H S$ was accumulated every $30 \mathrm{~min}$ and expressed as a percentage of the daily total solar radiation. Regardless of the period and solar radiation level, a common pattern of diurnal changes existed in relative $H S$ : it started to increase rapidly just before sunrise, peaked between 0730 and 0900 , then decreased linearly, bottomed out around 1800, and thereafter increased slowly until the following sunrise. The maximum and minimum percentages of $H S$ differed depending on the period and solar radiation level, but the difference remained small between solar radiation levels 2 and 3. It thus seemed possible to estimate $H S$ every $30 \mathrm{~min}$ based on the daily total solar radiation alone, by multiplying it with the percentage defined by the visually fitted dashed line (solar radiation level 1) or the solid line (solar radiation levels 2 and 3 ) shown in Fig. 10.

Figure 11 shows the relationship between the estimated and measured $H S$ every 30 min. Estimation was conducted based on the temperature change above the canopy using equations (11) and (12) (Fig. 11A), or from the daily total solar radiation using the dashed and solid lines in Fig. 10 (Fig. 11B). The root mean square

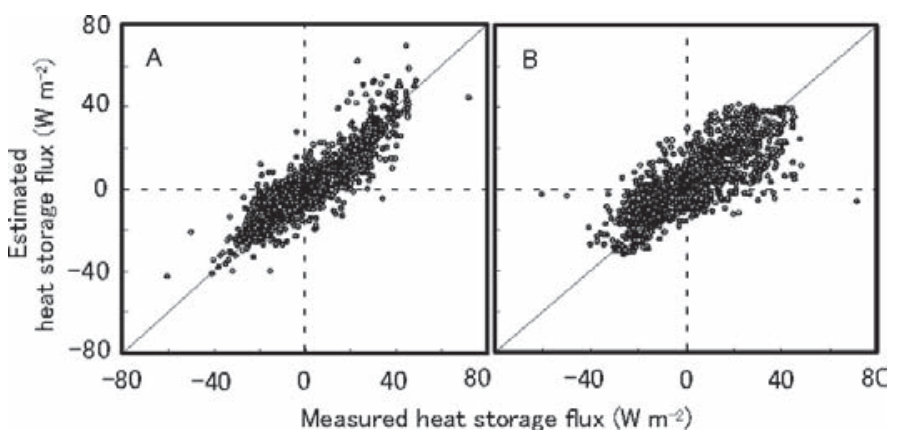

Fig. 11. Relationship between measured and estimated heat storage fluxes every 30 min. Estimation was conducted from (A) temperature change rate, or (B) percentage of daily solar radiation. 
errors (RMSEs) were $7.2 \mathrm{Wm}^{-2}$ when estimated from the temperature change, and $9.7 \mathrm{Wm}^{-2}$ when estimated from the solar radiation. The estimation from the solar radiation, although convenient because it uses only one datum per day, was often unsuccessful when large fluxes exceeding $40 \mathrm{Wm}^{-2}$ or below $-40 \mathrm{Wm}^{-2}$ were observed. At almost all the flux observation sites, the temperature observation is conducted above the canopy, hence temperature change data is available. Therefore, it seems more practical to derive the estimation of $H S$ from the temperature change above the canopy.

\section{Conclusion}

Our observations revealed that the maximum contribution term in the canopy heat storage in the apple orchard was $H S_{T}$, followed by $H S_{H}$ and $H S_{I E}$, while $H S_{L}$ was negligible. The diurnal fluctuation range of $H S$ was larger in the sprouting period than in the growing period, and on days of higher solar radiation. By taking $H S$ into account, the energy closure ratio for the eddy covariance method increased by 1.03 and 1.16 times in daytime and nighttime, respectively, and this increase was generally thought to improve the energy imbalance. $H S$ could be estimated reasonably well (RMSE $7 \mathrm{Wm}^{-2}$ ) using the air temperature data above the canopy.

\section{Acknowledgment}

This study was supported by a Grant-in-Aid for Scientific Research (C, 19580291).

\section{References}

Allen, R. G., Pereira, L. S., Raes, D., and Smith, M., 1998: Crop evapotranspiration: guidelines for computing crop water requirement. Irrig. And Drain. Paper, 56, FAO, Rome, 300pp.

Allen, R. G., Walter, I. A., Elliott, R. L., Howell, T. A., Itenfisu, D., Jensen, M. E., and Snyder, R. L., 2005: The ASCE Standardized Reference Evapotranspiration Equation. American Society of Civil Engineers, U.S.A., 216pp. (available at http://www. kimberly.uidaho.edu/water/asceewri/ on September 19, 2010)

Barr, A. G., Black, T. A., Hogg, E. H., Griffis, T. J., Morgenstern, K., Kljun, N., Theede, A., and Nesic, Z., 2007: Climatic controls on the carbon and water balances of a boreal aspen forest, 1994-2003. Global Change Biol., 13, 561-576.

Cava, D., Contini, D., Donateo, A., and Martano, P.,
2008: Analysis of short-term closure of the surface energy balance above short vegetation. Agric. For. Meteorol., 148, 82-93.

Fukuda, H., and Takishita, F., 1993: Comparison in dry matter production and assimilate partitioning between 'Jonagold' apple trees on an invigorating rootstock versus a dwarfing rootstock. J. Japan. Soc. Hort. Sci., 62, 513-517.

Gash, J. H. C., and Dolman, A. J., 2003: Sonic anemometer (co)sine response and flux measurement. I. The potential for (co)sine error to affect sonic anemometer-based flux measurement. Agric. For. Meteorol., 119, 195-207.

Ito, D., Ishida, S., and Matsushima, D., 2009: Longterm observation of $\mathrm{CO}_{2}$ flux by eddy covariance and Bowen ratio method in an apple orchard. Proc. Joint Conference on Environ. Engin. in Agric. 2009, A62 (in Japanese).

Ito, D., Sugiura, T., and Kuroda, H., 2006: Determination of evapotranspiration rate and estimation of daily evapotranspiration in a Japanese pear orchard. J. Agric. Meteorol., 62, 23-32 (in Japanese with English summary).

McCaughey, J. H., and Saxton, W. L., 1988: Energy balance storage terms in a mixed forest. Agric. For. Meteorol., 44, 1-18.

Meyers, T. P., and Hollinger, S. E., 2004: An assessment of storage terms in the surface energy balance of maize and soybean. Agric. For. Meteorol., 125, 105-115.

Michiles, A. A., and Gielow, R., 2008: Above-ground thermal energy storage rates trunk heat fluxes and surface energy balance in a central Amazonian rainforest. Agric. For. Meteorol., 148, 917-930.

Migliavacca, M., Meroni, M., Manca, G., Matteucci, G., Montagnani, L., Grassi, G., Zenone, T., Teobaldelli, M., Goded, I., Clolmbo, R., and Seufert, G., 2009: Seasonal and interannual patterns of carbon and water fluxes of a poplar plantation under peculiar eco-climatic conditions. Agric. For. Meteorol., 149, 1460-1476.

Miura, M., Hirano, T., Hirata, R., Mogami, J., Inukai, K., and Fujinuma, Y., 2003: Effect of heat storage flux on energy balance in a larch forest. J. Agric. Meteorol., 59, 245-250 (in Japanese with English summary).

Ohkubo, Y., Kosugi, Y., Takanashi, S., Matsuo, M., Tani, M., and Nik, A. R., 2006: Evaluation of the amount of storage in the forest space of a rainfor- 
est in Malaysia Peninsula. Proc. Joint Conference on Environ. Engin. in Agric. 2007, O-031215 (in Japanese).

Oliphant, A. J., Grimmond, C. S. B., Zutter, H. N., Schmid, H. P., Su, H.-B., Scott, S. L., Offerle, B., Randolph, J. C., and Ehman, J., 2004: Heat storage and energy balance fluxes for a temperate deciduous forest. Agric. For. Meteorol., 126, 185-201.

Skaar, C., 1988: Wood-water relations. Springer-Verlag, Berlin, 283pp.

Twine, T. E., Kustas, W. P., Norman, J. M., Cook, D. R., Houser, P. R., Meyers, T. P., Prueger, J. H., Starks, P. J., and Wesely, M. L., 2000: Correcting eddy-covariance flux underestimates over a grass- land. Agric. For. Meteorol., 103, 279-300.

Wada, T., Tani, M., Kosugi, Y., and Takanashi, S., 2002: Estimation of biomass heat storage in a Hinoki (Chamaecyparis obtusa) forest. For. Res. Kyoto, 74, 69-76 (in Japanese with English summary).

Wilson, K., Goldstein, A., Falge, E., Aubient, M., Baldocchi, D., Berbigier, P., Bernhofer, C., Ceulemans, R., Dolman, H., Field, C., Grelle, A., Ibrom, A., Law, B. E., Kowalski, A., Meyers, T., Moncrieff, J., Monson, R., Oechel, W., Tenhunen, J., Valentini, R., and Verma, S., 2002: Energy balance closure at FLUXNET sites. Agric. For. Meteorol., 113, 223-243. 